\title{
Hibriditas Multidimensional: Studi Kasus Karya Musik Komunitas Badan Gila
}

\author{
I Komang Sudirga \\ Program Studi Karawitan, Fakultas Seni Pertunjukan, \\ Institut Seni Indonesia Denpasar \\ email: komangsudirga@isi-dps.ac.id,
}

\begin{abstract}
This paper wants to show that the Komunitas Bada Gila (or Crazy Body Community) is an art community in Telepud Village, Tegalalang District, Gianyar Regency. This research is directed to answer questions related to the existence, aesthetic foundation, and creative processes that are behind the show. To answer these qualitative questions, this study applies various techniques and procedures for collecting data in the form of interviews and observations. I find that this community was founded in 2008 by 16 artists who have a commitment to devote their lives in the ecosystem of the art world. The idea to build this art community began with the Final Project of Artwork by Wayan Sutapa, which was inspired by genjek, the song that was played while drinking wine. Initially Sutapa aims to change the perception of traditional art which is considered as the 'art of the drunk' by placing it in a new context. However, instead of changing these negative perceptions, the works of the community have opened the possibility of expanding the creativity of kecak and genjek art into a more attractive form with the body as the medium. The creative works of the community reaffirm that Balinese society is open and a necessity for local-global struggle and association in Bali.
\end{abstract}

Keywords: multidimensional hybridity, musical work, kecak, genjek.

\section{ABSTRAK}

Tulisan ini ingin menunjukkan bahwa Komunitas Badan Gila adalah salah satu komunitas seni yang ada di Desa Telepud, Kecamatan Tegalalang, Kabupaten Gianyar. Penelitian ini diarahkan untuk menjawab pertanyaan-pertanyaan terkait dengan eksistensi, landasan estetis, dan proses kreatif yang ada dibalik pertunjukannya. Untuk menjawab pertanyaan kualitatif tersebut, penelitian ini menerapkan berbagai teknik dan prosedur mengumpulan data yang berupa, wawancara dan observasi. Penulis menemukan bahwa komunitas ini didirikan tahun 2008 oleh 16 orang seniman yang memiliki komitmen untuk mengabdikan hidupnya dalam ekosistem dunia seni. Ide membangun komunitas seni ini berawal dari Ujian Tugas Akhir Karya Seni oleh Wayan Sutapa yang terinspirasi dari genjek yaitu nyanyian yang dimainkan saat minum tuak. Awalnya Sutapa bertujuan mengubah persepsi seni tradisi yang dianggap sebagai 'seninya orang mabuk' ini dengan cara mendudukkan dalam konteks baru. Namun, alih-alih mengubah persepsi negatif tersebut, karya-karya komunitas ini telah membuka kemungkinan perluasan kreativitas seni kecak dan genjek ke dalam wujud yang lebih atraktif dengan tubuh sebagai mediumnya. Karya-karya kreatif komunitas ini meneguhkan kembali bahwa 
masyarakat Bali bersifat terbuka dan menjadi keniscayaan pergulatan dan pergaulan lokal-global di Bali.

Kata kunci: hibriditas multidimensional, karya musik, kecak, genjek.

\section{PENDAHULUAN}

Menghadapi kondisi dunia di era Revolusi Industri 4.0, setiap insan mau tidak mau mesti meningkatkan daya kretivitas dan daya saing agar mampu berkiprah dalam semangat jaman yang terus berubah. Sikap kritis dan berani hendaknya menjadi motivasi dalam era ini. Sikap kritis dibutuhkan untuk membaca situasi dan fenomena kebutuhan pasar, sedangkan sikap berani dibutuhkan untuk mengungkapkan gagasan dan ide-ide yang belum pernah ditawarkan orang sebelumnya ke dalam sebuah perwujudan hasil karya dan mendiseminasikan (publish).

Kemajuan sebuah kebudayaan sangat ditentukan oleh sikap kritis dan usaha kreatif para anggota masyarakatnya. Ciri sikap kreatif adalah keberanian untuk berubah. Tanpa perubahan. maka terjadi stagnasi dan monotonitas, sehingga hidup menjadi membosankan (boring). Inovasi adalah perubahan yang menyegarkan. Kehidupan yang penuh dengan tantangan persaingan memerlukan inovasi. Sikap hidup yang hanya puas dengan masa lalu hanyalah memelihara kebekuan dan menunggu ajal (Sudirga, 2017). Oleh karena itu, jangan pernah remehkan apalagi mengabaikan inovasi karena daya hidup kesenian akan tergantung dari spirit inovasi. Inovasi akan menjadi stimulan sekaligus sabagai lecutan untuk berkiprah ke dalam ruang-ruang kreativitas budaya yang membumi.

Arus budaya global yang mengalir deras bagikan air bah tentu sangat mengkhawatirkan sebagian kalangan akan tergerusnya nilai-nilai budaya lokal, namun masyarakat Bali sudah memiliki pengalaman panjang bersentuhan dengan budaya asing sehingga hal tersebut bukan dihindari tetapi diseleksi (filterisasi). Dalam banyak hal menunjukkan betapa interaksi budaya Bali dengan budaya Barat telah mampu memberikan tawaran nilai-nilai baru yang tidak hanya bermanfaat bagi perkembangan kebudayaan Bali tetapi juga untuk tujuan perkembangan nilai-nilai yang lebih universal.

Menghadapi kenyataan ini Giddens (2000:34) menyatakan bahwa kendatipun globalisasi berkecenderungan membawa jejak politik dan kekuasaan dari Barat yang 
dapat melemahkan kultur lokal, tetapi sekaligus membangkitkannya kembali. Ini berarti bahwa Globalisasi tidak semata-mata mengkhawatirkan tetapi juga memberikan harapan, optimisme yang mampu memantik munculnya spirit lokalitas, identitas, dan bahkan pergulatan lokal-global (glokalitas). Pergolakan dan pergulatan nilai-nilai budaya tradisi dan modern yang terus bergeliat dalam sebuah kubangan sehingga muncul fenomena tradisonalisasi di era globalisasi, dan mengglobalkan yang lokal. Fenomena ini menarik untuk dicermati terutama terkait fenomena glokalisasi dalam seni budaya Bali.

Proses ini ditunjukkan dari sikap beberapa pihak termasuk seniman menyikapi kondisi ancaman arus global tersebut sebagaimana dinyatakan Ardika (2005:18) bahwa anomali dan ambiguitas dalam kehidupan disadari atau tidak, telah menyebabkan ketidakseimbangan atau kehilangan orientasi (disorientasi) dan dislokasi pada setiap aspek kehidupan masyarakat. Kondisi ini secara tidak langsung memantik dorongan, prakarsa, serta ide seniman untuk merespons rasa kegelisahan yang tidak mau begitu saja menerima keadaan apalagi terlena dalam penetrasi halus hegemoni global. Hal ini berarti seniman yang kreatif selalu berusaha menancapkan ideologinya melawan dominasi budaya global dengan merespons situasi melalui spirit daya kreativitas tanpa henti dalam spirit ide-ide yang lebih baru. Munculnya sikap kritis ini tidak lepas dari strategi politik identitas seniman Bali yang merasa peduli untuk mempertahankan spirit identitas ke-Bali-annya. Selain itu, tuntutan ekonomi pasar global yang menstimulasi semangat inovasi menjadi landasan berkiprah dalam bingkai kerja kreatif. Terkait dengan fenomena tersebut penulis tertarik untuk mengkaji salah satu komunitas seni yang memiliki spirit inovasi berbingkai industri kreatif dalam balutan seni tradisi.

Salah satu komunitas seni yang menarik perhatian peneliti adalah Komunitas Badan Gila (Kobagi). Komunitas ini cukup menarik perhatian penulis karena disamping produksi hasil karyanya kreatif inovatif juga cara kerjanya yang melibatkan seniman asing secara kolaboratif.

\section{METODE PENELITIAN}

Artikel ini merupakan hasil pengamatan peneliti terhadap Komunitas Badan Gila (Kobagi) di Desa Telepud, Kecamatan Tegalalang, Kabupaten Gianyar. Penelitian ini diarahkan untuk menjawab pertanyaan-pertanyaan terkait dengan 
eksistensi, landasan estetis, dan proses kreatif yang ada dibalik pertunjukannya. Untuk menjawab pertanyaan kualitatif tersebut, penelitian ini menerapkan berbagai teknik dan prosedur mengumpulan data yang berupa, wawancara dan observasi. Wawancara terutama dilakukan kepada pimpinan Komunitas Badan Gila, yakni I Wayan Sutapa, S.Sn seorang alumni dari program Studi Seni Karawitan, Fakultas Seni Pertunjukan, Institut Seni Indonesia (ISI) Denpasar. Semenara, observasi dalam penelitian ini berupa pengamatan terhadap proses latihan dan pertunjukanpertunjukan Kobagi.

\section{PEMBAHASAN}

Kobagi muncul di sebuah Desa Telepud, Kecamatan Tegalalang, Kabupaten Gianyar. Komunitas ini didirikan tahun 2008, beranggotakan 16 orang seniman yang memiliki komitmen untuk mengabdikan hidupnya dalam ekosistem dunia seni. Ide membangun komunitas seni ini berawal dari Ujian Tugas Akhir Karya Seni oleh Wayan Sutapa yang terinspirasi dari seni genjek yaitu seni olah vakal dengan dibarengi minum tuak. Pendukung karya ujian Tugas Akhir ini kemudian dihimpun untuk memenuhi obsesi seorang Sutapa yang ingin mengubah persepsi seni tradisi ini sebagai seni orang mabuk, dan mendudukkan dalam konteks baru agak tidak tergerus jaman dan dilupakan oleh generasi muda.

Untuk merealisasikan gagasannya ini Sutapa mencoba membangun komunitas yang tidak memerlukan modal kapital yang besar. Muncullah ide untuk mengkemas musik dengan alat yang murah meriah yakni potongan-potongan bambu, suling, alat yang ada di sekitar lingkungan seperti "keles" atau kele yang dikombinasikan dengan vokal dan body music. Media lain yang juga tidak perlu mengeluarkan banyak biaya adalah gamelan mulut seperti genjek dan kecak menjadi inspirasi memperkaya content garapan yang bernuansa teatrikal dengan balutan musik kerakyatan yang eksotis.

Seiring perkembangan waktu, kehadiran seorang Marcello Pretto dari Francis mampu memberikan warna baru dalam produksi karya Kobagi. Bagaimana tidak eksplorasi body music lebih instens dilakukan dengan memanfaatkan segala anggota tubuh seperti tepukan tangan, hentakan kaki, suara mulut, pukulan tanagan ke pipi, ke paha dan ke badan dieksplorasi (jelajah) lebih kaya dengan pola ritme yang variatif. Tampaknya seorang musisi Perancis Grégoire Gensse yang akrab 
dipanggil Made Bagus ini mengembangkan Barbatugues (body musical form) sebagai landasan kerja kreatifnya yang dikombinasikan dengan unsur-unsur percusion musik dunia termasuk perkusi musik Bali ke dalam ekspresi berbagai pola atau bentuk-bentuk ritme yang ditransformasikan. Cara kerjanya juga cukup menarik misalnya kekilitian atau jalinan pukulan cengceng kopyak ditransfer ke dalam hentakan pukulan tangan atau mulut. Demikian juga pola-popa ritme kendang ditransfer dalam hentakan-hentakan kaki atau tangan ke tubuh.

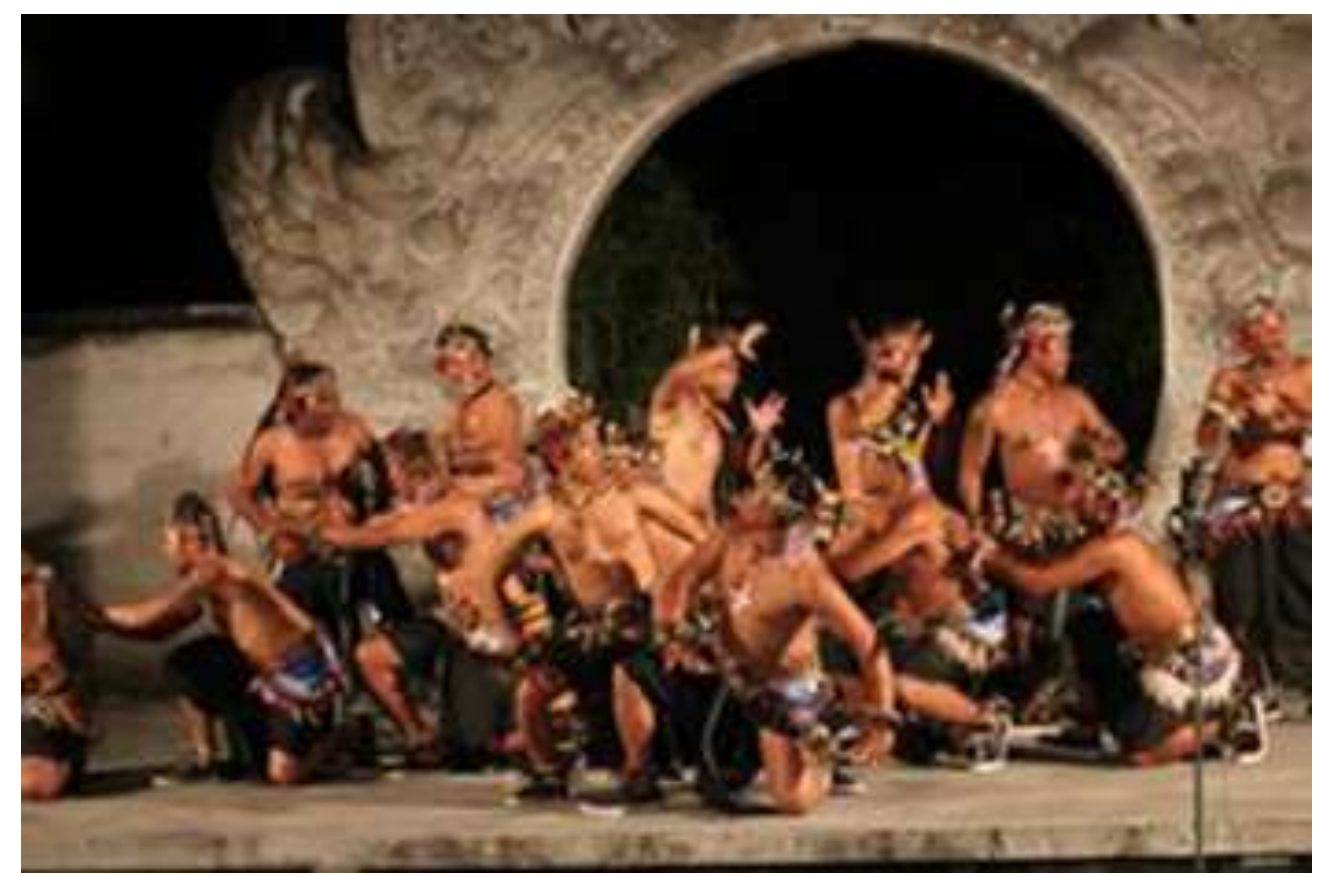

Gambar 1:

Pementasan Kobagi di Bentara Budaya Bali

(Foto: dokumentasi Bentara Budaya Bali)

Pertautan antara musik dan cara berkesenian Barat dengan Timur (Bali) tecermin dari kekhasan penampilan Kobagi, terutama menjadikan tubuh sebagai perkusi yang senafas, selaras dengan irama atau intensitas dari ragam olah vocal kecak Bali. Kedua sekaa atau komunitas ini disandingkan sekaligus dibandingkan sebagai gambaran betapa kesenian di Bali begitu terbuka untuk melakukan proses akulturasi dan kemungkinan kolaborasi yang nyatanya menghasilkan bentuk-bentuk baru yang kreatif dan memukau tanpa kehilangan spirit kekuatan estetik tradisi Balinya. 


\section{Sikap Terbuka dan Peduli}

Menurut Ida Bagus Mantra (1993) menghadapi tantangan kebudayaan baru kita tidak boleh konservatif, berpikiran kuno. Kita mesti bersikap terbuka namun selektif. Jadi kita mesti bersikap terbuka, fleksibel artinya membuka diri terhadap perkembangan jaman namun selektif dalam menerima pengaruh luar yang sesuai dengan kepribadian bangsa kita. Perkembangan kebudayaan baru jangan sampai lepas dari akar kebudayaan kita.

Apa yang dipesankan oleh Budayawan kesohor Bali itu patut direnungkan. Karena jika, orang Bali terlalu tertutup maka kebudayaan kita akan stagnan. Jika terlalu bebas menerima pengaruh luar juga akan berdampak terhadap kesinambungan kebudayaan terutama rentan terhadap hilangnya jati diri dan identitas ke-Bali-an kita. Dalam konteks inilah sikap kreatif yang menjunjung nilainilai kearifan lokal menemukan relevansinya. Apalagi menghadapi arus budaya global yang tidak mungkin dapat kita bendung di era kesejagatan ini. Dalam konteks demikian sikap peduli akan keberpihakan terhadap pemertahanan dan pelestarian nilai-nilai budaya lokal menjadi penting untuk di kedepankan. Dalam tataran ini mencermati kinerja seniman yang tergabung dalam komunitas Kobagi tampaknya menarik untuk didiskusikan.

Kepedulian sikap budaya Kobagi ini diwujudkan melalui sikap kreatif, apresiatif, partisipatif, dan sikap bangga akan warisan seni budaya tradisinya. Sikap budaya ini menjadi pilar benteng dan tiang penyangga yang sangat penting. Sebagaimana dinyatakan Davis (dalam Geriya,2008:170) kokoh atau bobolnya ketahanan sebuah kebudayaan tergantung dari sikap masyarakat pendukung kebudayaan tersebut sebagai penyangganya.

Perubahan dalam dimensi kultural bagaimanapun akan mengacu pada perubahan suatu kebudayaan dalam masyarakat akibat adanya penemuan (discovery) dalam bidang ilmu pengetahuan, pembaruan hasil (invention) teknologi, kontak dengan kebudayaan lain yang menyebabkan terjadinya difusi dan peminjaman kebudayaan. Munandar (1998: 117) menyatakan dimensi perubahan kultural meliputi hal-hal sebagai berikut:

Inovasi kebudayaan seperti penemuan, peniruan, peminjaman, dan alat-alat; difusi, seperti penyimpangan kebudayaan dan difusi secara benar; integrasi, seperti penolakan terhadap bentuk-bentuk baru, duplikasi, cara hidup lama 
dan baru bersama-sama dalam variabel pola-pola, pergantian bentuk-bentuk lama dengan bentuk-bentuk baru.

Sikap terbuka seniman Bali dalam hal ini Sutapa, untuk menerima gagasan dari budaya asing dan memadukannya dalam karya seninya yang baru telah melahirkan bentuk seni kolaboratif dalam dunia musik vokal Bali sebagaimana juga Wayan Dibia dengan Keith Terry dalam memadukan elemen musik Barat dan kecak Bali dalam wujud karya kolaborasi "Body Tjak".

\section{Kobagi sebagai Inovasi Hibrida}

Istilah hibridisasi dipinjam dari ilmu kedokteran yakni mengawinkan dua jenis hewan atau tumbuhan yang berbeda varietas dan memiliki sifat-sifat unggul. Hibiridisasi juga bisa didapat dengan cara mutasi gen dan inseminasi buatan (kawin suntik). Keuntungan mengembangbiakkan tanaman dan hewan dengan memperhatikan sifat unggul. Konsep ini diadopsi untuk mengembangkan keunggulan beberapa genre musik tradisi dan barat untuk menghasilkan (produksi) musik baru yang lebih kreatif dan menyuguhkan kesan dan warna yang berbeda dari musik-musik sebelumnya.

Terminologi Hybrid Theory sendiri mulai dikenal dikalangan pecinta musik lewat album Linkin Park yang pertama dan kedua, disamping itu istilah ini juga sudah dikenal luas oleh kalangan para scientist khususnya orang-orang yang bergelut di bidang Ilmu Biologi dan Genetika. Hybrid dapat juga diartikan sebagai kawin silang. Persilangan budaya seperti ini dalam dunia musik juga sering disebut sebagai musik hibrid. Fenomena musik Hibrid di Bali telah terjadi sejak Bali membuka diri sebagai daerah tujuan wisata dunia. Kedatangan Collin mcPhee yang banyak meneliti musik tradisi Bali telah menyusun komposisi musik dengan bermaterikan dari reportoar musik Bali. Selanjutnya proses apropriasi atau pinjam meminjam dalam dunia seni khususnya dalam bidang musik bergelinjang, saling meminjam bahkan satu sama lain bermetamorfose, membentuk genre musik baru..

Persilangan budaya seperti ini dalam dunia musik juga sering disebut sebagai musik hibrid. Dalam konteks musik hibrid yang menjadi sasaran utama adalah menyilangkan dua genre musik sebagai varietas unggulan yang dapat menelorkan varietas musik baru yang khas, unik, dan mencirikan keunggulannya. Hasil produksi baru tersebut tak jarang juga dinilai sebagai seni produk akulturasi. Dalam konteks 
seni musik akulturasi ditekankan bahwa Kobagi tersebut merepresentasikan dua unsur kebudayaan yang lahir dari proses tertentu membentuk seni yang melebur namun masih mengejawantahkan elemen budaya asing (global) dengan elemen budaya asli (lokal). Seperti halnya teknik olah vokal, tepukan tangan, eksplorasi bunyi mulut, body music, dari Barat dipadukan dengan teknik olah vokal Bali, cecandetan, kekilitan cak, gamelan mulut (genjek, cakepung) yang merepresentasikan elemen musik Bali. Pola kerja akulturatif seperti ini telah terjadi dalam dunia seni musik vokal sudah sejak lama. Sebagai contoh seni cakepung sebagai 'orang tuanya' seni genjek di Bali merupakan perpaduan seni olah vokal antara budaya Bali dengan budaya Sasak. Cakepung muncul akibat kontak kebudayaan antara orang-orang Bali dengan orang-orang Sasak pada masa kekuasaan raja-raja Bali Karangasem di Sasak (Lombok) sejak pertengahan abad XVIII.

Hubungan cakepung dengan genjek sangat bertautan. Struktur penyajian Genjek tak jauh berbeda dengan cakepung. Hanya saja cakepung lebih steoretif, susah berkembang akibat unsur instrinsik yang kuat, seperti penguasaan tembang sesasakan sebagai identitas sajiannya. Tanpa pernah hidup dalam budaya dan tradisi Sasak tentu sangat sulit dapat menyajikan irama tembang sesasakan yang menjadi penciri utama dalam sajian tembang-tembangnya. Sementara genjek hanya mengadopsi struktur luarnya sedangkan konten tembangnya dapat saja diadopsi dari jenis tembang Bali seperti gegendingan (sekar rare), sekar alit (macapat), lagu pop Bali, bahkan jenis dangdut koplo. Sifat Genjek yang lebih fkelsibel menjadikan genjek lebih cepat populer. Sifat dinamisnya sangat disukai berbagai kalangan dan tidak mengherankan jika mampu menembus batas generasi muda milenial.

\section{Reproduksi Kebudayaan}

Kobagi sebagai ekspresi budaya merupakan hasil reproduksi kebudayaan. Kobagi lahir dari bentukan persilangan kebudayaan antara kebudayaan lokal Bali dengan kebudayaan barat. Kebudayaan Bali terutama seni tembang, Cak dan Genjek, serta musik Bali bermediakan instrumen dari berbagai ukuran potongan Bambu, suling, dan kele, dikemas dengan sajian musik Barbatuges (body musik) dari Barat. 
Bentuk-bentuk reproduksi kebudayaan seperti ini juga tampak dari keberadaan cakepung sebagai seni tradisi kemudian menginspirasi munculnya kesenian genjek. Genjek dapat dikatakan sebagai reproduksi baru dari cakepung. Hubungan cakepung dengan genjek sangat bertautan. Struktur penyajian genjek tak jauh berbeda dengan cakepung. Hanya saja cakepung lebih steoretif, agak sulit berkembang. Walaupun telah diupayakan dengan berbagai eksperimen menggunakan lakon baru tetap saja stagnan. Hal mana sebagai akibat unsur instrinsik yang kuat, seperti penguasaan tembang sesasakan sebagai identitas sajiannya. Tanpa pernah hidup dalam budaya dan tradisi Sasak tentu sangat sulit dapat menyajikan irama tembang sesasakan yang menjadi penciri utama dalam sajian tembang-tembangnya. Sementara genjek hanya mengadopsi struktur luarnya, seperti memulai dengan jenis tembang solo, kemudian disahut secara bersama untuk beberapa frase, terakhir dengan noreng yakni irama seperti pengecet dimana seorang memainkan melodi utama sementara yang lain menirukan bunyi-bunyi berbagai instrumen dengan berbagai variasinya. Untuk konten tembangnya dapat saja diadopsi dari jenis tembang Bali seperti gegendingan (sekar rare), sekar alit (macapat), lagu pop Bali, bahkan jenis dangdut koplo ataupun irama jazz. Sifat genjek yang lebih fkelsibel menjadikan genjek lebih cepat populer. Sifat dinamisnya sangat disukai berbagai kalangan termasuk para dokter dan tenaga medis dan tidak mengherankan jika mampu menembus batas generasi muda milenial.

\section{Musik Hibrid dalam Berbagai Ekspresi Budaya}

Pada perkembangan berikutnya musik hibrid dimaknai sebagai persilangan antara kebudayaan lokal dengan kebudayaan asing seperti halnya kebudayaan Hindu, Budha, Islam, dan Barat. Kebudayaan etnis lokal nusantara bersentuhan dengan kontak-kontak kebudayaan global membentuk kebudayaan baru sebagai sebuah hasil persilangan budaya. Demikian halnya dalam bidang musik terjadi persilangan budaya musik yang unik, khas, dan asli Indonesia. Menurut Victor Ganap (2015), musik keroncong adalah hasil akumulasi dari berbagai elemen barat (Portugis dan Belanda) dan non Barat (arab, Afrika, India, Tiongkok, Oceania, Betawi, dan Jawa.) Musik Campursari adalah fenomena musik hibrida. Bukan saja berhasil memadukan musik tradisional dan modern dengan apik, melainkan juga melahirkan genre musik baru yang unik dan asli Indonesia. Banyak yang menilai 
Campursari melahirkan spirit merevitalisasi musik Keroncong, bahkan menjadi perkembangan secara mutakhir dari genre keroncong langgam Jawa dalam kemasan musik modern. Proses persilangan budaya dalam dunia musik ini kemudian memunculkan komunitas-komunitas baru sebagaimana yang terdapat dalam Batuan Etnik Fusion pimpinan Balawan, kemudian Bona Alit, Pala Wara pimpinan Ary Wijaya, Jes Gamelan Fusion pimpinan Nyoman Windha, Emony Bali, dan Kobagi sendiri. Bahkan dalam perhelatan lomba lagu pop daerah yang mencoba mensilangkan antara unsur musik Barat dengan musik Bali.

Dalam kaitan dengan konsep hibriditas salah satu Komunitas Badan Gila (Kobagi) pimpinan Wayan Sutapa dalam karyanya juga merepresentasikan berbagai elemen musik modern terutama dari Barbatugues (body music form) yang dimainkan bersama-sama dengan jenis alat musik tradisional seperti gangsa (saron), kendang, cengceng, suling, gong, dan instrumen Bali lainnya dimainkan dengan mulut (acapela) walhasil menghasilkan warna bunyi yang hormani nan indah. Bunyibunyian dari mulut mereka berpadu dengan lagu spontanitas yang bersahutan menuju puncak, diikuti aneka gerak badan dan tangan secara lepas bebas, meluapkan keriangan sekaligus kehangatan persahabatan. Genjek yang merupakan musik vokal yang identik dengan konsep kemabukan itu dimaknai ulang dan diterjemahkan jadi ekspresi seni yang otentik-kontemporer. Warih Wisatsana dalam esainya di media Kompas merilis penampilan Kobagi di Bentara Budaya 27 April 2014 berkomentar:

"Mereka menari, menepuk pipi, lengan, perut dan kaki. Sekujur badan penari lain dipukul bagaikan perkusi, menimbulkan irama-irama nan ritmis lagi dinamis. Saking musikalnya tubuh para penari, suara desah napas kelelahan yang mewarnai pertunjukan pun terasa menyatu padu.Gerakangerakan mereka seolah ingin membebaskan diri ke dalam suatu ketaksadaran yang lain: bahwa setiap jengkal tubuh beserta daya hidupnya adalah musik yang tak tergantikan. Hanya saja, mereka mementaskannya secara sadar, tanpa pengaruh tuak. Pada puncak pertunjukan, yang teraih adalah sebentuk ekstase, di mana publik turut terhanyut tercerahkan (Wisatsana, 2014).

Elaborasi kreatif Kobagi dapat dibaca sebagai cerminan fenomena Bali era kini. Paduan ciri kecak dan genjek dengan olah gestur yang nyaris mirip capoeira Amerika Latin serta dekonstruksi konsep tubuh sebagai subyek sekaligus obyek musikal, merefleksikan baurnya kelokalan Bali dengan dinamika keglobalan. Apa 
yang dilakukan Kobagi bukan semata-mata gejala musikal tetapi ada upaya secara diskursif untuk mewacanakan elemen-elemen musikal secara teknis dan politis menuju pentas musik yang lebih fenomenal, "nakal", dan eksperimental dengan konsep-konsep aktual. Interpretasi ulang terhadap laku kreatif dibangun tanpa menunggu ketaksadaran diri sebagaimana umumnya pengaruh alkolohik dari minuman tuak sebagai ikoniknya. Mereka menampilkan konsep bermusik secara sadar namun mampu menghasilkan aura musikalitas yang penuh greget, sebentuk ekstase yang katarsis.

Sejak didirikan tahun 2008, Kobagi telah menampilkan kreasinya di berbagai acara kebudayaan, dan secara perlahan turut mengubah persepsi publik perihal genjek sebagai seni yang sarat mabuk-mabukan. Pola kolaborasi ini, antara Kobagi dengan Gregorie Gensse, menjadi keniscayaan pergaulan lokal-global di Bali, meneruskan kerja-kerja kolaboratif antara seniman Bali dengan seniman asing seperti Ari Smith, Walter Spies, R. Bonet dengan seniman lukis Bali yang mewujud dalam Sanggar Pitamaha, begitu pula kolabotrasi Limbak dengan Walter Spies, Sardono dengan seniman Teges dalam kolaborasi garapan Cak, serta Keith Terry dengan Wayan Dibia dalam kolaborasi Body Tjak, serta Seniman Makaradwaja Singapadu dengan Bryan Bamboos dan Group Kwartet Music dari Amerika dalam garapan Paras Paros.

Sebagai komunitas yang memiliki jati diri baru dalam penampilannya, Kobagi telah beberapa kali meramaikan berbagai even festival seperti Perayaan Hut Kota Klungkung, Ubud Festival, Sanur Vilagge Festival, Raintforest Kucing-Serawak World Music Festival (2015), dan Kobagi telah beberapa kali berpentas dan mengisi pertunjukan di Bentara Budaya Bali, antara lain pertunjukan genjek "Dari Singamandawa hingga Kobagi“, serta mengisi pertunjukan dalam pembukaan pameran Asian Watercolor Expression II dan Pameran Suka Parisuka, Yogyakarta, dan yang lainnya.

Mencermati konsep bermusik secara hibriditas dalam dimensi yang lain, terutama dalam perhelatan karya-karya Tugas Akhir mahasiswa Fakultas Seni Pertunjukan ISI Denpasar, baik karya dari Program Studi (Prodi) seni Karawitan maupun Prodi Musik juga bermunculan karya-karya inovasi yang mengusung media dari seni tradisi asli (lokal) sebagai upaya pengukuhan terhadap identitas dan eksplorasi kearifan budaya lokal kemudian memadukan dengan elemen-elemen 
budaya asing (baik budaya nusantara ataupun budaya Barat). Inovasi lainnya juga muncul dengan memadukan antara elemen musik vokal kecak dengan konsepkonsep musik Balaganjur dalam wujud garapan "Cak Ganjur". Garapan ini juga tanpa instrumentasi musik secara fisik melainkan semua lagu dimainkan dengan mentransformasi pola-pola musikal ke dalam body music dan juga musik mulut (akapela). Walaupun tanpa instrumen garapan ini cukup kaya dengan konsepkonsep inovasi terutama dalam olah garap pola-pola musikal yang dibalut dengan konsep teatrikal sehingga menghasilkan sajian karya seni bernuansa baru, dengan spirit callenging yang kuat.

Konsep bermusik dan menari secara simultan (koreomusikologi) menjadi tantangan tersendiri dalam sajian musik Bali masa kini. Tidak saja dalam komunitas Kobagi dan Cak Ganjur, dalam perhelatan musik Balaganjur pun kini dituntut tidak saja terampil memainkan alat musik tetapi juga harus mampu bermain sambil 'menari'. Dengan konsep seperti itu seorang pemusik Bali hendaknya menguasai aspek teknis dan aspek mental. Seperti misalnya mampu mengatur energi (ngunda bayu), mengatur suara (ngunda sabda) dan mengatur nafas (ngunda angkihan), dan mengatur konsentrasi (ngunda idep). Di samping itu alur dan gerakan musik yang cepat dan dinamis tentu menjadi persoalan teknis tersendiri dalam menata kemasan pertunjukan agar tampil mengalir menarik dan mampu mengundang daya pikat dan memukau penonton. Kemampuan aspek keterampilan teknis yang tinggi dibarengi dengan aspek mental yang saling mendukung maka akan mampu menghasilkan sajian karya seni sarat dengan spirit "taksu"

\section{SIMPULAN}

Kobagi adalah buah eksplorasi musikal dari efek gerak dan bunyi yang melahirkan genre pertunjukan baru dalam komposisi musik dan gerak tari yang rancak. Kolaborasi kreatif antara seniman Bali yang dimotori Wayan Sutapa dengan seniman Perancis Gregorie Gense sejak 2008 membuka kemungkinan perluasan kreativitas kecak dan genjek ke dalam wujud seni yang lebih atraktif dengan tubuh sebagai mediumnya. Kobagi telah menampilkan kreasinya dalam wujud reproduksi kebudyaan dan telah menampilkan hasil karyanya di berbagai acara perhelatan kebudayaan Kerja kreatif Kobagi secara perlahan turut mengubah persepsi publik perihal genjek sebagai seni yang sarat mabuk- 
mabukan. Hadirnya seniman asing dalam kerja kreatif ini semakin meneguhkan bahwa Masyarakat Bali bersifat terbuka dan menjadi keniscayaan pergulatan dan pergaulan lokal global di Bali. Bahkan tidak dipungkiri telah terjadi 'glokalitas' yakni yang global dilokalkan.

Dalam berbagi dimensinya kerja kreatif seperti ini telah melahirkan ragam seni pertunjukan baru dalam wujud musik hibrid. Pencapaian Kobagi mencerminkan juga sebentuk pola perubahan, di mana seni tradisi bertemu modernitas melahirkan aneka kemungkinan penciptaan berikut jalan simpangnya masing-masing. Pada ambang batas tertentu, tecermin dalam perkembangan estetik dan bentuknya, kini muncul pula garap-garap musikal dengan berbagai dimensi yang memperkaya perluasan kerja kreatif dengan laku kreatif yang tidak hanya bermediumkan instrumen belaka namun memadukan instrumen dengan vokal, akapela dengan body musik melalui eksplorasi tubuh.

Mereka menari, menepuk pipi, lengan, perut dan kaki. Sekujur badan lain dipukul bagaikan perkusi, menimbulkan irama-irama nan ritmis lagi dinamis., dan kecenderungan terakhir adalah konsep koreomusikologi dimana setiap pemain musik dituntut juga untuk bermain sambil menari sebagaimana dalam fenomena Body Tjak, Kobagi, dan Cak Ganjur.

Menghadapi tantangan dunia musik masa depan yang rentan akan menimbulkan disorientasi dan stereotype di kalangan generasi knservatif maka perlu dibangun sikap kritis, dengan cara merevitalisasi, mereinterpretasi, dan dekonstruksi pemikiran atas nama sakralitas dan pelestarian "kaku yang membeku" agar tumbuh daya kreatif yang "cair" berorientasi kekinian dengan makna-makna filosofis yang tanpa tercerabut dari jangkar kepribadiannya.

\section{REFERENSI}

Ardika, I Wayan. 2005. "Strategi Bali Mempertahankan Kearifan Lokal di Era Global," dalam Darma Putra \& Windhu Sancaya (ed.) Kompetensi Budaya Dalam Globalisasi. Denpasar : Fakultas Sastra UNUD dan Pustaka Larasan.

Ganaf, Victor. 2015. Popularitas musik Hibrid. http//boleh merokok.com. diakses 9 desember 2019.pukul 14.00

Geriya, I Wayan. 2008. Transformasi Kebudayaan Memasuki Abad XXI. Surabaya: Paramitha.

Giddens, Anthony. 2001. Runaway World: Bagaimana Globalisasi Merombak Kehidupan Kita. Jakarta: Gramedia Pustaka Utama. 
Mantra, I.B.1993. Bali Masalah Sosial Budaya dan Modernisasi. Sukaya Sukawati (ed.). Denpasar : Upada Sastra.

Sudirga, I Komang. 2005. Cakepung Ansambel Musik Vokal Bali. Yogyakarta: Kalika.

Wisatsana, Warih, 2014. Lokal Global KOBAGI. http//Bentara Budaya.com, diakses, 12 Desember 2014. 